\title{
Surgical Treatment of Unstable Posterior Wall Acetabular Fractures - A Cross Sectional Study
}

\author{
Malay Kumar Saha ${ }^{1 *}$, Mohammad Jahangir Alam², Rezaul Karim³ , Md. Zakir Hossain ${ }^{4}$, \\ Joyosree Paul ${ }^{5}$ \\ ${ }^{1}$ Associate Professor, Unit Chief, Department Of Orthopaedic Surgery, MBBS, D-Ortho, MS-Ortho, \\ Mymensingh Medical College, Mymensingh, Bangladesh \\ ${ }^{2}$ Professor, National Institute of Traumatology and Orthopaedic Rehabilitation, Dhaka, Bangladesh \\ ${ }^{3}$ Associate Professor, National Institute of Traumatology and Orthopaedic Rehabilitation, Dhaka, Bangladesh \\ ${ }^{4}$ Associate Professor and Classified Specialist, Dept. of Otolaryngology \& Head-Neck Surgery, MBBS, MCPS, \\ DLO, FCPS, FACS (USA), FRCS (Glasg), Combined Military Hospital, Dhaka Cantonment, Dhaka, \\ Bangladesh \\ ${ }^{5}$ Medical Officer (OPD), Mymensingh Medical College Hospital, Mymensingh, Bangladesh
}

\begin{abstract}
*Corresponding Author: Malay Kumar Saha, Associate Professor, Unit Chief, Department of Orthopaedic Surgery, MBBS, D-Ortho, MS-Ortho, Mymensingh Medical College, Mymensingh, Bangladesh.
\end{abstract}

\begin{abstract}
Background: Acetabular fractures are severe injuries, generally caused by high-energy trauma, most frequently from traffic accidents or falls from heights. Fractures of the extremities, head, chest, abdomen and pelvic ring injuries are most commonly associated injuries.
\end{abstract}

Aim: To evaluate the results of surgical treatment of unstable posterior wall fractures with open reduction and internal fixation.

Patients and Methods: This study is a cross sectional study. It included 16 patients who have unstable fractures of posterior wall of acetabulum, it ranged from 20- 60 years with mean $32.8 \pm 9.12$ years. They were 12 males and 4 females. The cause of trauma was road traffic accident (RTA) in all patients. All patients were operated upon with open reduction and internal fixation using reconstruction plates and cancellous screws for treatment of posterior acetabular fracture in the period from October 2016 to September 2018 with follow up period ranging from 2 months to 2 years, in National Institute of Traumatology \& Orthopaedic Rehabilitation (NITOR), Dhaka, Bangladesh.

Results: Satisfactory functional outcome was obtained in 12 cases, excellent in 5 and good in 7 cases, while unsatisfactory functional outcome was obtained in 4 cases, fair in 3 and poor in one.

Conclusions: Open reduction and internal fixation is an effective method for treatment of unstable posterior acetabular wall fractures. Surgical treatment leads to early re-habilitation and avoiding complications as osteoarthritis.

Keywords: Fracture of Posterior Wall Acetabulum, Open Reduction, Internal Fixation.

\section{INTRODUCTION}

Acetabular fractures are caused by high-energy trauma, with traffic accidents, especially automobile accidents being their main causes. The increase in the number of vehicles circulating and their greater speed has increased the incidence of these fractures and decreased the age at which they occur (1). Acetabular fracture was an enormous orthopaedic problem in which the treatment was grossly inadequate and many patients were left with incapacitating pain (2). Acetabular fractures are severe injuries, most frequently caused by a highenergy trauma. Fractures of the extremities, head, chest, abdomen and pelvic ring injuries are the most commonly associated injuries (3). Open anatomical reduction of the articular surface in displaced acetabular fractures, rigid internal fixation and early mobilization has become a standard treatment for these injuries $(4,5)$. A successful anatomical reduction of the 
articular surface of the acetabulum allows an adequate contact between the acetabulum and the femoral head, as well as a normal pressure distribution on the hip joint. Anatomical reduction prevents post-traumatic osteoarthritis, and a stable internal fixation enables normal functioning of the hip joint (6). Reconstruction plates which can be contoured and bend along the contour of acetabulum are most commonly used with combination of cancellous cannulated screws. Screw penetration into the hip joint during operation is an unusual but potentially serious complication (7). Acetabular fractures in the posterior column, particularly involving the danger zone, are the most common form of acetabular fracture, they remain technically challenging to the orthopaedic surgeons. The danger zone of the acetabulum, is that part of the posterior wall and column at the midacetabulum lying above the ischial spine, is frequently used in the fixation of posterior wall and posterior column. Screws directed perpendicular to posterior column in the danger zone would violate the hip joint (8). Proper screw placement can avoid the complication. No matter what the method, obtaining an excellent long term result in the treatment of acetabulum fractures is dependent on restoring a congruent and stable hip joint with an anatomically reduced articular surface $(9,10)$. The achievement of these objectives minimizes pain, prevents post traumatic osteoarthritis, and improve long term functional outcome. However, fractures of the acetabulum continue to be a challenge for the orthopaedic surgeon. Successful treatment of an acetabular fracture is based on a thorough under-standing of the complex three dimensional anatomy of the innominate bone (11). This study was to review the displaced posterior acetabular fractures treated operatively in our hospital with regards to clinical, radiological results, the rate of surgical complication and the rate of successful fracture reduction. The purpose of this study was to evaluate the results of open reduction and internal fixation of posterior displaced acetabular fractures. The open anatomical reduction of the articular surface combined with rigid internal fixa-tion and early mobilization have become the standard treatment for these injuries.

\section{Patients and Methods}

This study is a cross sectional study. It included 16 patients who have unstable fractures of posterior wall of acetabulum. They were included during the duration from October 2016 to September 2018, in National Institute of Traumatology \& Orthopaedic Rehabilitation (NITOR), Dhaka, Bangladesh. Inclusion criteria were acute clinical unstable posterior wall displaced acetabular fractures with or without dislocations or sciatic nerve palsy associated with unstable hip. Age of the patients ranged from 20- 60 years with the mean \pm SD was $32.8 \pm 9.12$ years. Road traffic accident was the mode of trauma. Right side acetabular fractures were more common than left sided fractures. All cases were operated within 1 to 2 weeks of trauma. Posterior wall acetabular fractures were more common seen in 14 cases and 2 cases were posterior column fractures. Primary management of acetabular fractures was done. Then, radiological assessment with three standard plain radiographs (one anteroposterior (AP) and two oblique views) was done. In addition, two-dimensional computed tomography (CT) scan and a three-dimensional CT scan was also done. In 2 patients who have posterior acetabular fracture which was associated with hip dislocation, closed reduction under general anesthesia was done on emergency basis and patients were put on skeletal traction and surgical treatment was performed as soon as the patient's general medical condition allowed with reconstruction plate $3.5 \mathrm{~mm}$ and cancellous screws $4 \mathrm{~mm}$. Patients were operated under spinal or general anesthesia. For all patients Kocher Langenbeck (K-L; posterior) approach was used. Indications of K-L approach were as the following: 1) displaced acetabular fractures with or without dis-location, 2) presence of osteochondral intra articular fragments or 3) unstable hip and associated sciatic nerve palsy.

\subsection{Surgical Procedure}

All patients were prepared and draped in a lateral position. All fractures were exposed and stabilized through K-L approach as described by Magu et al (12) in lateral position with the affected hip on the upper side. The approach started by cleaning off the soft tissue debris between the fractured fragments and preservation of the attached capsular soft tissues. The osteochondral free fragments in the hip joint were removed and the extent of marginal impaction was recognized by the application of gentle traction at the hip joint. Then reduction of posterior wall fragments and their attached capsular ligaments was done and maintained with a pointed ball spike. Using a ball spike instrument leads to reduction of the necessity of momentary fixation by Kirschner 
wires. Kirschner wires were sometimes used provisionally till final fixation was done. All patients treated with open reduction and internal fixation with reconstruction plate $3.5 \mathrm{~mm}$ and cancellous screws $4 \mathrm{~mm}$. The smallest fragments were discarded when they were disconnected from their soft tissues. After fixation, intra-articular reduction was confirmed with gentle traction at the hip joint and by a stability test. Care was taken to confirm that the lag screws that were placed close to the posterior rim were extrarticular. The wounds were closed in layers over suction drainage tubes. The drains were removed at $48-72 \mathrm{hrs}$ post-operative. Active assisted and pain free passive range of motion exercises in all planes was advised. Postoperatively, patients were instructed to use crutches on the affected extremity. Partial weight bearing was allowed after 6 weeks and full weight-bearing with a single crutch or a cane after 10-12 weeks. Unprotected weight bearing was advised after complete healing of the fracture. The final follow-up images were graded according to the criteria developed by Matta (13). According to these criteria, "a grade of excellent is given to a normal appearing hip joint, good denotes mild changes with minimal sclerosis and joint narrowing, fair indicates intermediate changes with moderate sclerosis and joint narrowing $(<50 \%)$ and poor signifies advanced changes". At the final follow-up investigation, the functional outcome was evaluated using a modified Merle d'Aubigne and Postel as modified by Matta (13). Patients were followed up initially at 3 weeks interval for first 2 months and thereafter at 6 weekly intervals for next 6 months. Any complications occurred during the follow up period were documented.

\subsection{Statistical Analysis}

The collected data were organized, tabulated and statistically analyzed using statistical package for social science (SPSS) version 19.0 (SPSS Inc., Chicago, USA) soft-ware computer package running on IBM compatible personal computer. For numerical variables, mean, standard deviation, and range were calculated; while for categorical variable, frequency (number) and percent distribution were calculated.

\section{Results}

Males were affected more than females. The operative time ranged from 2 to 3 hours. All patients treated with open reduction and internal fixation with reconstruction plate $3.5 \mathrm{~mm}$ and cancellous screws $4 \mathrm{~mm}$. The intra-operative blood loss ranged from $1000 \mathrm{cc}$ to $1500 \mathrm{cc}$ and all patients received blood transfusion. The hospital stay after surgery averaged 10 days (715). Radiological union occurred in all patients at a mean of 4 months (3-5). At a mean follow up of 12 months (2-24) using a modified scoring system of Merle Daubigue, the satisfactory functional out-come was obtained in 12 cases (Table 1), excellent in 5 and good in 7 cases, while the unsatisfactory functional outcome was obtained in 4 cases, fair in 3 and poor in one. The twelve patients with satisfactory functional outcome had perfect to near perfect postoperative fracture reduction, while the four unsatisfactory functional outcomes have a good postoperative fracture reduction. Partial weight bearing was done at $8-10$ weeks in $75 \%$ of patients; $10-12$ weeks in $12.5 \%$ and more than 12 weeks in $12.5 \%$.

Table1. Distribution of cases in relation to radiological union/months, and patients' satisfaction $(N=16)$

\begin{tabular}{|l|l|l|l|}
\hline $\begin{array}{l}\text { Radiological } \\
\text { union/months }\end{array}$ & $\begin{array}{l}\text { Duration of } \\
\text { Union }\end{array}$ & $\begin{array}{l}\text { No } \\
(\mathbf{1 6})\end{array}$ & $\mathbf{\%}$ \\
\hline & Three months & 2 & $12.5 \%$ \\
\hline & Four months & 7 & $43.8 \%$ \\
\hline & Six months & 4 & $25 \%$ \\
\hline & Eight months & 3 & $18.8 \%$ \\
\hline $\begin{array}{l}\text { Patients' } \\
\text { satisfaction }\end{array}$ & Yes & 12 & $75 \%$ \\
\hline & No & 4 & $25 \%$ \\
\hline
\end{tabular}

Table2. Distribution of studied patients as regard to Partial and full -weight bearing $(N=16)$

\begin{tabular}{|l|l|l|l|}
\hline & Period & No (16) & \% \\
\hline \multirow{3}{*}{$\begin{array}{l}\text { Partial wearing } \\
\text { beari }\end{array}$} & $<8$ weeks & 0 & 0 \\
\cline { 2 - 4 } & $8-10$ weeks & 12 & $75 \%$ \\
\cline { 2 - 4 } & $10-12$ weeks & 2 & $12.5 \%$ \\
\cline { 2 - 4 } & $>12$ weeks & 2 & $12.5 \%$ \\
\hline \multirow{2}{*}{$\begin{array}{l}\text { Full-weight } \\
\text { bearing }\end{array}$} & $<12$ weeks & 2 & 0 \\
\cline { 2 - 4 } & $12-16$ weeks & 14 & $87.5 \%$ \\
\cline { 2 - 4 } & $>16$ weeks & 2 & $12.5 \%$ \\
\hline
\end{tabular}

Table3. Distribution of studied subjects as regard to complications $(N=4)$

\begin{tabular}{|l|l|l|}
\hline Complications & No. & \% \\
\hline $\begin{array}{l}\text { Superficial wound } \\
\text { infection }\end{array}$ & 2 & $12.5 \%$ \\
\hline Post traumatic arthritis & 1 & $6.25 \%$ \\
\hline $\begin{array}{l}\text { Partial sciatic nerve } \\
\text { neuropraxia }\end{array}$ & 1 & $6.25 \%$ \\
\hline
\end{tabular}

The full weight bearing duration were at $12-16$ weeks in $87.5 \%$ and more than 16 weeks in $12.5 \%$ (Table 2). The complications were reported in 4 patients: in the form of superficial wound infection in 2 patients $(12.5 \%)$, post- 
traumatic arthritis in 1 patient $(6.25 \%)$, and partial sciatic nerve neuropraxia in 1 patient $(6.25 \%)$ (Table 3). Pre-and post-operative

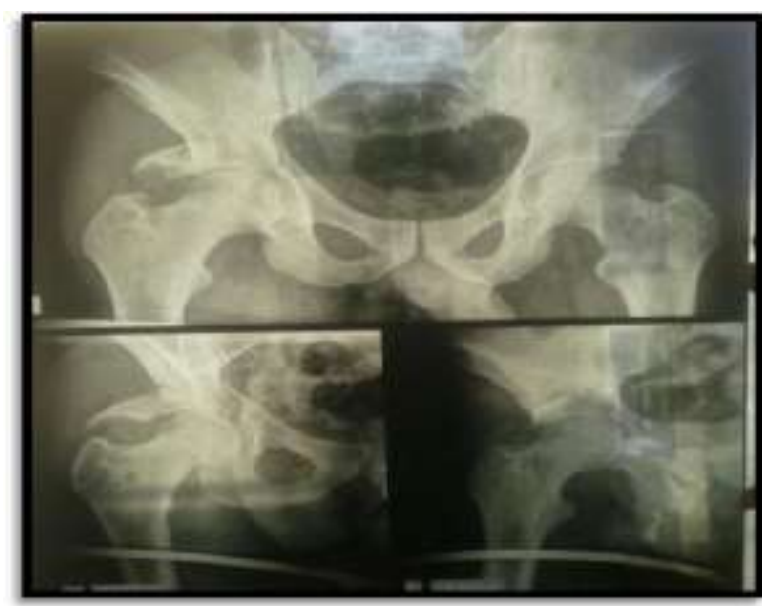

Fig. 1a. $X$ - ray AP view of the pelvis showing fracture posterior wall of acetabulum

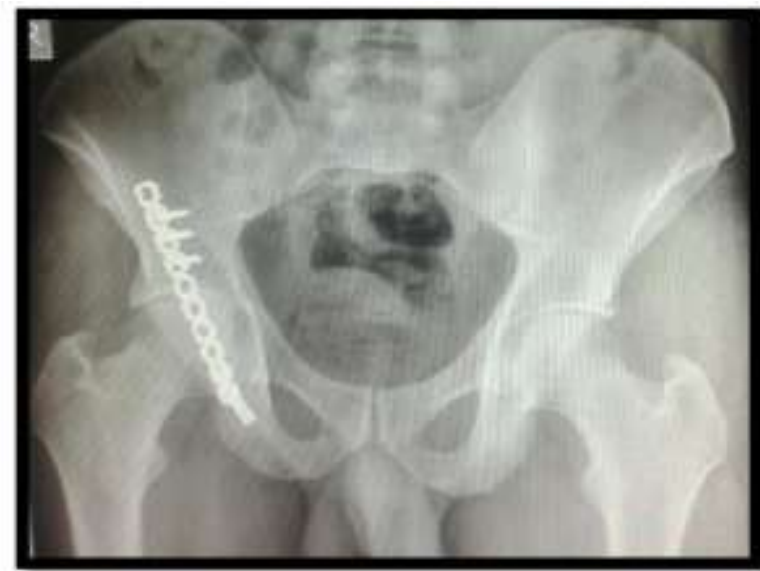

Fig. 1c. Immediate postoperative $x$ ray showing fixation of the posterior wall with reconstruction plate and cancellous screws radiological images of two cases were presented in figures 1 and 2.

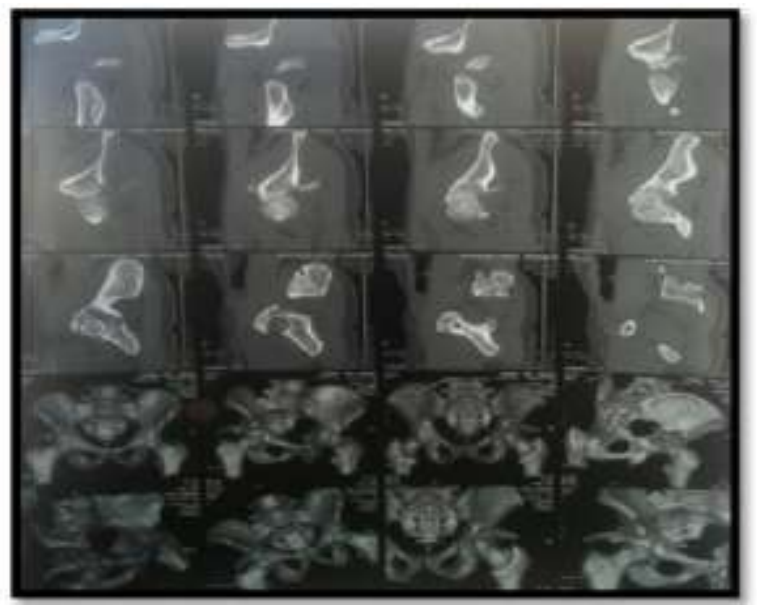

Fig. 1b. CT showing posterior wall acetabular fracture

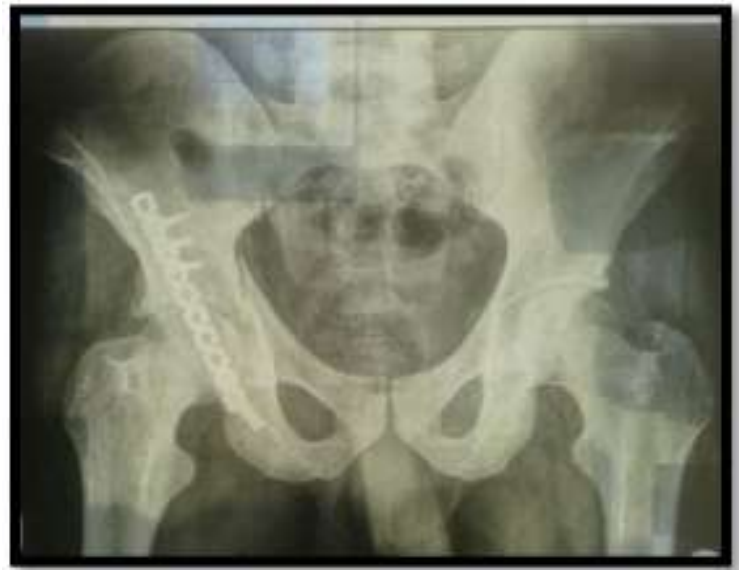

Fig. 1d. 12 months postoperative showing complete union

Figure1. Pre-and post-operative figures of case 1

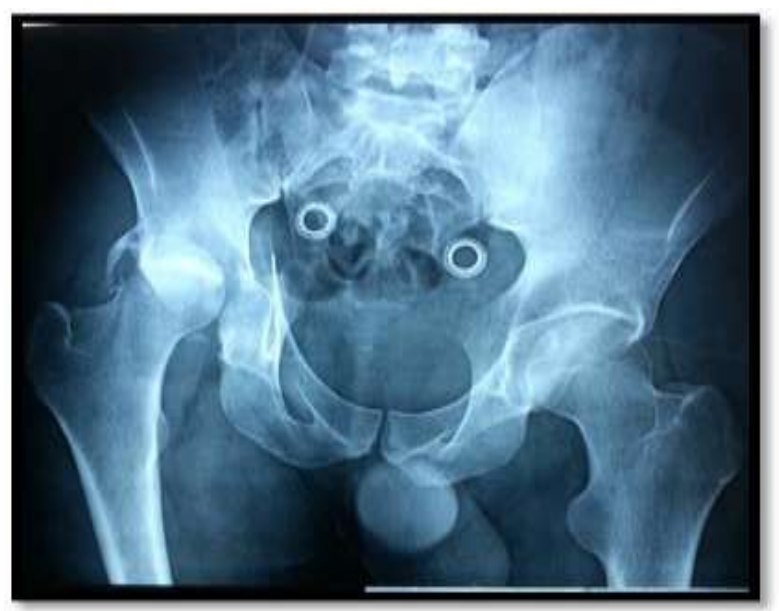

Fig. 2a. Oblique view showing posterior acetabular fragment with instability of hip joint

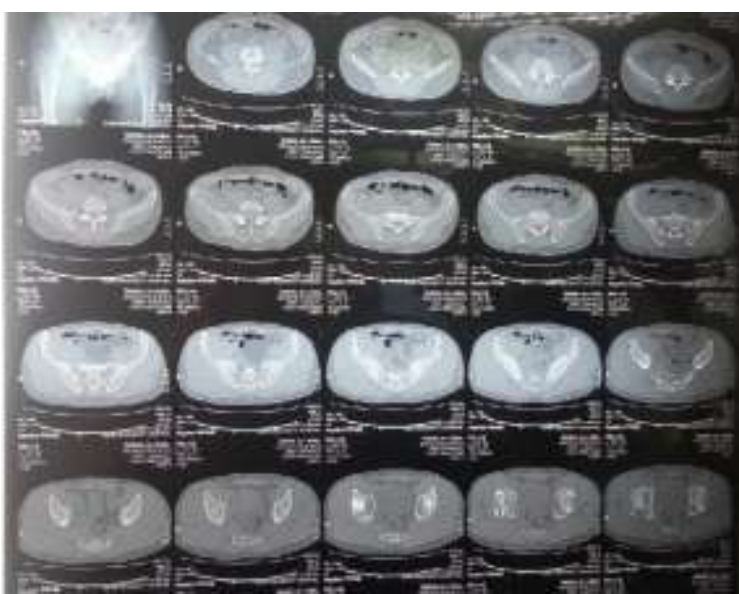

Fig. 2b. Axial cut CT showing posterior acetabular fracture 


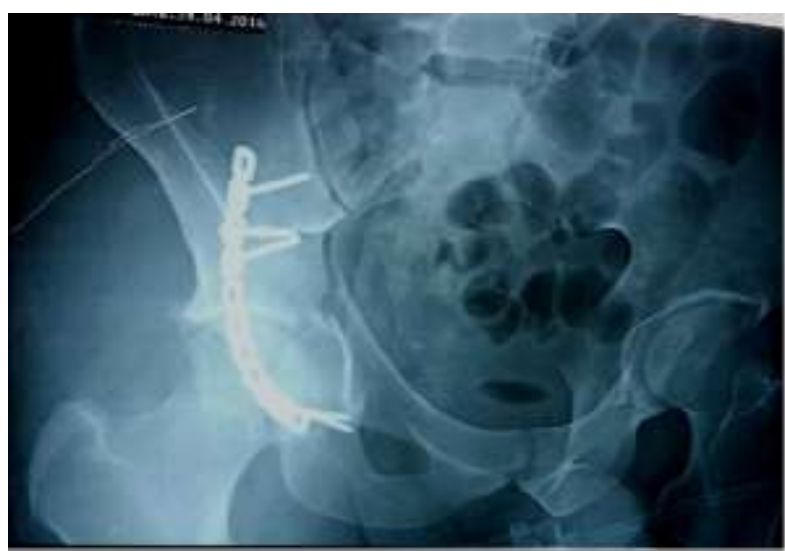

Fig. 2c. Postoperative oblique view showing good reduction

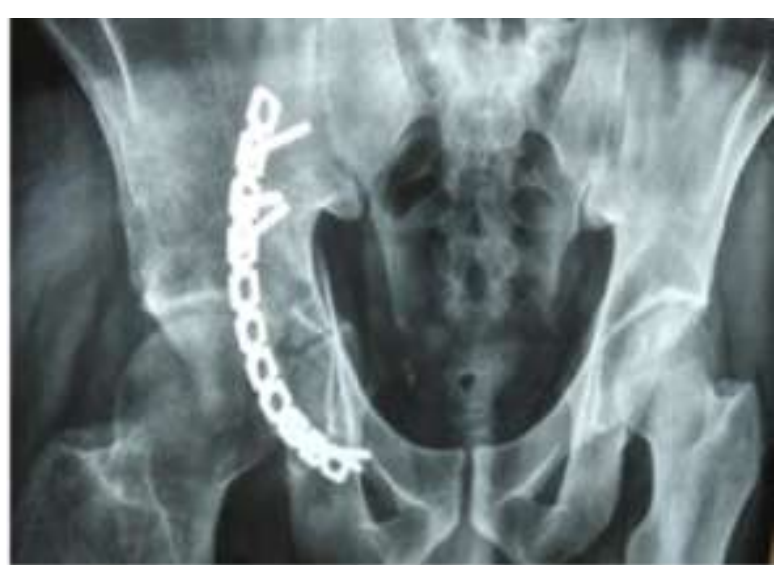

Fig. 2d. 4 months postoperative showing fracture healing

Figure2. Pre-and post-operative figures of case 2

\section{DisCUSSION}

Posterior acetabular fractures are difficult fractures to treat due to complex fracture configuration, difficult surgical approaches and precarious blood supply of acetabulum (14). These are intra-articular fractures involving the hip joint which need to be appropriately managed to restore near normal anatomy and mobility otherwise morbidity and disability will be the outcome $(15,16)$. Here, authors presented their experience with the management of the posterior wall acetabular fractures. Authors used the Kocher Langhenbeck approach for reconstruction of posterior wall acetabular fracture as it is considered to be appropriate for posterior acetabular fractures as it gives adequate exposure for reduction of all posterior wall and posterior column fractures. It is possible to achieve early mobilization of the patient which helps in healing of the fracture and prevents joint stiffness (5). In the present work, authors encouraged their patients for early mobilization after surgery with permission of early weight bearing exercises as early as it was possible. This agrees with previous work, where it was reported that, early weight bearing and rehabilitation is possible with good postoperative mobilization protocol and physiotherapy. Individualized approach and adoption of minimally invasive surgerygives better results (17). The overall outcome of the studied subjects was satisfactory as regard to radiological union, and patient satisfaction. This may be attributed to the proper selection of surgical procedure and good anatomical reduction intraoperatively. These results agree with previous literature. It was reported that, the accuracy of reduction is an important predictor of functional outcome. The approximation to normal anatomy will depend on the complexity of the fracture and the expertise of the surgeon. Thus, reconstruction of the posterior wall acetabular fracture with open reduction and internal fixation produces well to excellent results in majority of patients with acceptable rate of complication. They provide a stable fixation with good joint congruency of the hip joint amenable to early range of motion and weight bearing (18). In addition, it was reported that, open reduction and internal fixation of posterior acetabular fractures are the treatment of choice in displaced fractures (11). In the present study, Harris hip scoring was used in evaluation of functional outcome. Results revealed that, it improved with each visit. In our study, satisfactory functional outcome was obtained in 12 cases (75\%), excellent in 5 and good in 7 cases, while the unsatisfactory functional outcome was obtained in 4 cases $(25 \%)$. These results are comparable to the study of Gupta et al (20) with good outcome in $69.5 \%$. In the present work, road traffic accident was the most common cause of fracture (All patients were due to road traffic accident), and this is line with previous work reported that, acetabular fractures occur frequently and are most common in road traffic accidents. Road traffic accidents are increasing day by day due to multiple reasons. Ignorance of traffic principles, poor traffic system and deficiency of road safety are adding insult to the incidence of this dilemma. Acetabular fractures are most often associated with multiple injuries (15). Sixteen patients were included in the present study, age ranged from 20- 60 years with the mean of $32.8 \pm 9.12$ years, while it was 36.8 years in another study conducted by Rao et al (19). It reflects that the age group of patients suffering from acetabular fractures belongs to 
younger age group. Male preponderance was evident in the present work, and it was in line with the study done by Rao et al (19). In the present work, the surgical intervention was done as early as possible after stabilization of patients. This may be associated with good results. This is in agreement with previous work reported that, in displaced acetabular fractures, surgical intervention should be done as early as possible. They added, by doing this good result can be obtained (14). In present work, most of cases were operated upon within 2 weeks after trauma and it resulted in good outcome. Another study conducted by Gupta et al (20) also showed good results when surgery was done within 2 weeks after injury. In the present study, congruent reduction in $77 \%$ of the patients while it was 76.91 in Gupta et al (20). Regarding complications, the rate of infection in Gupta et al (20) was $7.9 \%$ while in the present work; it was observed in 2 cases (12.5\%). In addition, one patient $(6.25 \%)$ in the present work, developed sciatic nerve neuropraxia compared to $3.17 \%$ in Gupta et al (20). In another study conducted by Rommens et al (21), it was $8.3 \%$. Proper sterilization technique leads to no deep infection in the present study. In the present study, no cases with heterotopic ossification. In addition, none of the patient developed DVT. One limiting step of the present study is the small number of cases included in the present work. In addition, the short term follow up represented another weak point of the present study. Thus, it is recommended to do future studies with inclusion of large number of subjects and extend the duration of follow up for 3 years at least.

\section{CONCLUSION}

The effective method for the management of displaced acetabular fractures is operative treatment. Open reduction and internal fixation within two weeks usually associated with good results. Clinical and radiological results correlate closely with an anatomic reduction, and Kocher Langenbeck approach had a good outcome.

\section{REFERENCES}

[1] Giehl JP, Kluba T, Jager G. Acute ace-tabular fracture following non-convulsive muscular contraction. ActaOrthopScand 2000; 71(5):530-1.

[2] Laflamme GY, Hebert-Davies J, Rou-leau D, Benoit B, Leduc S. Internal fix-ation of osteopenic acetabular frac-tures involving the quadrilateral plate. Injury 2011; 42(10):1130-4.
[3] Moed BR, WillsonCarr SE, Watson JT. Results of Operative Treatment of Fractures of the Posterior Wall of the Acetabulum, J Bone Joint Surg Am 2002; 84-A (5):752-8.

[4] Kim HT, Ahn JM, Hur JO, Lee JS, Cheon SJ. Reconstruction of Acetabu-lar Posterior Wall Fractures. Clin Or-thop Surg. 2011; 3(2): 11420.

[5] White G, Kanakaris NK, Faour O, Valverde JA, Martin MA, Giannoudis PV. Quadrilateral plate fractures of the acetabulum: an update. Injury 2013; 44(2):159-67.

[6] Archdeacon MT, Kazemi N, Collinge C, Budde B, Schnell S. Treatment of pro-trusio fractures of the acetabulum in patients 70 years and older. J Orthop Trauma 2013; 27(5):256-61.

[7] Giordano V, Pecegueiro do Amaral N, Franklin CE, Pallottino A, Pires E, Al-buquerque R, and Giordano M. Functional outcome after operative treatment of displaced fractures of the acetabulum. Eur J Trauma Emerg Surg 2007; 33 (5): 52-7

[8] Prasartritha T, Chaivanichsiri P. The study of broken quadrilateral surface in fractures of the acetabulum. Int Or-thop 2013; 37(6):1127-34.

[9] Cornell CN. Management of acetabu-lar fractures in the elderly patient. HSS 2005; $1(1): 25-30$.

[10] Marintschev I, Gras F, Schwarz CE, Pohlemann $\mathrm{T}$, Hofmann GO, Culemann Biomechanical comparison of dif-ferent acetabular plate systems and constructs-the role of an infraacetabular screw placement and use of locking plates. Injury 2012; 43(4):470-4.

[11] Keel MJ, Ecker TM, Siebenrock KA, Bastian JD. Rationales for the Bernese approaches in acetabular surgery. Eur Trauma Emergency Surg. 2012; 38(5):489-98.

[12] Magu NK, Rohilla R, Arora S, More H. Modified Kocher-Langenbeck ap-proach for the stabilization of posteri-or wall fractures of the acetabulum. J Orthop Trauma 2011; 25(4):243-9.

[13] Matta JM. Fractures of the acetabu-lum: Accuracy of reduction and clinical results in patients managed operative-ly within three weeks after the injury. Bone Joint Surg Am. 1996; 78(11):1632-45.

[14] Bastian JD, Tannast M, Siebenrock KA, Keel MJ. Mid-term results in relation to age and analysis of predictive fac-tors after fixation of acetabular frac-tures using the modified Stoppa ap-proach. Injury 2013; 44(12):1793-8.

[15] Liu Y, Yang H, Li X, Yang SH, Lin JH. Newly modified Stoppa approach for acetabular fractures. Int Orthop 2013; 37(7):1347-53. 
[16] Kim JW, Herbert B, Hao J, Min W, and Ziran BH, Mauffrey C (2015): Acetabu-lar fractures in elderly patients: a comparative study of low energy ver-sus high-energy injuries. Int Orthop, 2015; 39:1175-9.

[17] Park MS, Yoon SJ, Park JH, Choi SM. The management of the displaced medial wall in complex acetabular fractures using plates and additional cerclage. Hip Int: J Clin Exp Res Hip Pathol Ther, 2013; 23:323-9.

[18] Daurka JS, Pastides PS, Lewis A, Rick-man M, Bircher MD. Acetabular frac-tures in patients aged >55 years: a sys-tematic review of the literature. Bone Joint J, 2014; 96-B (2):157-63.
[19] Rao VS, Chandrasekhar P, Rao AL, Rao VB. Results of surgically treated dis-placed acetabular fractures Among Adults. Clin Proc NIMS, 2008; 17:22-5.

[20] Gupta RK, Singh H, Dev B, Kansay R, Gupta P, Garg S. Results of operative treatment of acetabular fractures from the third world-how local fac-tors affect the outcome. IntOrthopj 2009; 33(2):347-52.

[21] Rommens PM, Giménez MV, Hess-mann M. Posterior wall fractures of the acetabulum: characteristic, man-agement, prognosis. Acta Chir Belg 2001; 101(6):287-93

Citation: Malay Kumar Saha, Mohammad Jahangir Alam, Rezaul Karim, Md. Zakir Hossain, Joyosree Paul. Surgical Treatment of Unstable Posterior Wall Acetabular Fractures - A Cross Sectional Study. 2020; 5(2):29. 35. DOI: https://doi.org/10.20431/2456-0588.0502005.

Copyright: (C) 2020 Authors. This is an open-access article distributed under the terms of the Creative Commons Attribution License, which permits unrestricted use, distribution, and reproduction in any medium, provided the original author and source are credited. 